\title{
Aschbacher and Caffarelli Awarded 2012 Wolf Prize
}

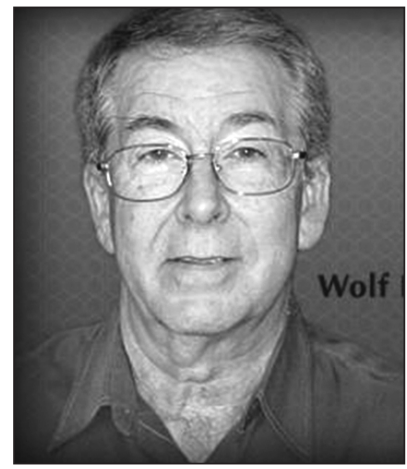

Michael Aschbacher

The 2012 Wolf Prize in Mathematics has been awarded to:

Michael AschbaCher, California Institute of Technology, for his work in classifying finite simple groups.

LUIS CAFFARELLI, University of Texas, Austin, for his work on partial differential equations.

The prize of US $\$ 100,000$ was divided equally between the prizewinners. The list of previous recipients of the Wolf Prize in Mathematics is available on the website of the Wolf Foundation, http://www.wolffund.org.i1.

\section{Description of the Prizewinners' Work}

The following descriptions of the prizewinners' work were prepared by the Wolf Foundation.

Michael Aschbacher and John Thompson (Wolf Prize laureate of 1992) are the two great modern masters of the theory of finite groups in an era that brought to fruition a line of research going back to Galois in the 1830s. The breadth and depth of Aschbacher's understanding of finite groups in general, and finite simple groups in particular, and the power he brought to bear on their analysis are astonishing.

Aschbacher astounded the finite group theory community with a series of papers that raised the classification project for finite simple groups from a distant dream to the reality it is today.

In a series of papers in the 1970s Aschbacher developed the theory of standard components

DOI: http://dx.doi.org/10.1090/noti980 and tightly embedded subgroups and brought the theory of groups of odd characteristic type close to completion.

Turning next to groups of characteristic type, Aschbacher handled all of the most difficult cases, notably the Thin Group case, the $p$-Uniqueness Case, and finally the Quasithin Case. This last result, contained in two massive monographs written jointly with S. D. Smith, completed the classification of finite simple groups. In the process, he significantly advanced the theories of $G F(2)$ representations, Thompson factorization, and pushing up.

Also worthy of mention are Aschbacher's work on maximal subgroups of finite simple groups, his joint work with Y. Segev on the uniqueness of the sporadic groups, and his joint work with S. D. Smith on the Quillen conjecture.

Caffarelli has repeatedly made very deep breakthroughs. His early work on free boundary problems was the first place where his extraordinary talent and intuition began to show. Free boundary problems are about finding both the solutions to an equation and the region where the equation holds. In a series of pioneering papers, Caffarelli put forward a novel methodology which eventually leads, after several truly amazing technical estimates that step by step improve the regularity of the solutions and the boundary, to full regularity under very mild assumptions. Although the theory is complicated, the arguments are elementary and full of beautiful geometric intuition and mastery of analytic technique.

A second fundamental contribution by Caffarelli is the study of fully nonlinear elliptic partial differential equations (including the famous Monge-Ampère equation), which he revolutionized. The upshot is that, although the equations are nonlinear, they behave for purposes of regularity as if they were linear. (Work of Nirenberg, Spruck, Evans, Krylov, and others also played a significant role here.)

Another fundamental contribution by Caffarelli is his joint work with Kohn and Nirenberg on partial 
regularity of solutions of the incompressible Navier-Stokes equation in 3 space dimensions. Although the full regularity of solutions is still unknown and likely very hard, Caffarelli-KohnNirenberg showed that the singular set must have parabolic Hausdorff dimension strictly less than one. In particular, singular fibers cannot occur. (V. Scheffer also deserves partial credit.)

Caffarelli has also produced deep work on homogenization and on equations with nonlocal dissipation. The list could be continued. Caffarelli is the world's leading expert on regularity of solutions of partial differential equations.

\section{Biographical Sketches}

Michael Aschbacher was born in 1944 in Little Rock, Arkansas. He received his B.S. from the California Institute of Technology in 1966 and his Ph.D. from the University of Wisconsin, Madison, in 1969. He joined the faculty of the California Institute of Technology in 1970 and is currently Shaler Arthur Hanisch Professor of Mathematics at Caltech. He was a visiting scholar at the Institute for Advanced Study in 1978-1979. He was awarded the Cole Prize in Algebra (1980), the Rolf Schock Prize of the Royal Swedish Academy of Sciences
(2011), and the Leroy P. Steele Prize for Mathematical Exposition (2012). He has been elected to the National Academy of Sciences (1990) and is a fellow of the American Academy of Arts and Sciences (1992) and of the American Mathematical Society (2012).

Luis Caffarelli was born in 1948 in Buenos Aires, Argentina. He received his Master of Science (1968) and Ph.D. (1972) degrees from the University of Buenos Aires. He has taught at the University of Minnesota, the University of Chicago, the Courant Institute of Mathematical Sciences at New York University, and the Institute for Advanced Study. He is currently the Sid W. Richardson Foundation Regents Chair in Mathematics at the University of Texas at Austin. He has received the Bôcher Memorial Prize (1984), the Rolf Schock Prize (2005), and the Leroy P. Steele Prize for Lifetime Achievement (2009). He is a member of the National Academy of Sciences (1991) and a fellow of the American Mathematical Society (2012).

\title{
Platonism Is the Law of the Land
}

\author{
David A. Edwards
}

It is a well-established principle of our legal tradition that mathematical formulas, laws of nature, and natural phenomena are not patentable subject matter. It is the purpose of this essay to argue that this tradition should be reversed. Our argument is that it is and always has been in our society's economic self-interest to grant very broad intellectual property rights. This is particularly important in our present Information Age where "software dominates."

The patent system is designed to promote the flow of technological innovation, a topic of much current concern in America. One often sees references to the relative decline in American vs. foreign patents as evidence of a decline in American innovation. But the main frontier of current technological innovation is in software, and software

David A. Edwards is associate professor of mathematics (retired) at the University of Georgia. His email address is dedwards@math.uga.edu.

DOI: http://dx.doi.org/10.1090/noti975 is not patentable. In fact the patent office itself has argued repeatedly against the patentability of software because it would be flooded with applications. ${ }^{1}$ This implies a very active software industry much desirous of patent protection.

At present, only those things which are made by man are patentable. Thus, the courts have allowed new forms of bacteria which have been engineered to have useful properties using recombinant DNA techniques to be patented but would not allow such a bacterium to be patented if it were naturally occurring even if it were newly discovered. This is the basis for the nonpatentability of computer programs. They are algorithms, which are essentially mathematical formulas, which-as everyone knows-are "eternal" and hence discovered by man and not created by him. This argument which,

${ }^{1}$ Harold T. Johnson Jr. Comment "Computer program patentability - the CCPA refuses to follow the lead of the Supreme Court in Parker v. Flook", North Carolina Law Review 58(1980), 319. 